\title{
Phenolic compounds, total antioxidant capacity and volatile components of Cabernet Sauvignon red wines from five different wine-producing regions in China
}

\author{
Bao JIANG ${ }^{1 *}$, Zhan-Yu SUN ${ }^{1}$
}

\begin{abstract}
The purpose of this study was to elucidate the influence of terroir on the polyphenolic compounds, total antioxidant and aroma components of Cabernet Sauvignon red wines from five different wine-producing regions in China. The results obtained showed that the phenols concentrations and total antioxidant capacities from new wine 1 (NW1) were significantly the highest among five regional wines, the latter were new wine 3 (NW3), old wine 1 (OW1) and new wine 2 (NW2), these parameters in old wine 2 (OW2) were the lowest. But the contents of total anthocyanins in the NW2 was higher than both OW1 and NW3. All 58 and 51 volatile components were separately detected in three "new regions" and two "old regions" wines, the volatile fraction was constituted mainly alcohols, esters and acids. According to odor descriptor of these compounds, cheese, floral and fruity aroma was conferred the three new regional wines. The phenol, total antioxidant capacity and aroma components of Cabernet Sauvignon wines can be affected by environmental factors of terroirs in the different extent; three "new regions" have a big potential for producing high quality Cabernet Sauvignon wines.
\end{abstract}

Keywords: wine; phenolic compounds; antioxidant capacity; volatile compounds; China.

Practical Application: Three new terroirs have a big potential for producing high quality Cabernet Sauvignon red wines.

\section{Introduction}

Grape berries are rich in phenolic compounds in human diet. Phenolic compounds, originated from grape berries, are transformed into wine through the wine fermentation process. Phenolic compounds not only contribute to the quality of wine, such as appearance, mouthfeel and stability of red wines, but also play an important role in antioxidant activity, cardiovascular protection and anti-cancer (Katalinić et al., 2010; Kim et al., 2011; Stockham et al., 2013). Volatile is one of the most important factors, which determines the quality and style of each regional wine (Rodriguez-Nogales et al., 2009), therefore influences on consumer preference. The volatile compounds come from grape berries, fermentation and ageing process (Rapp, 1998), so volatile compounds in wine are much more complex than those in grape berries. To date, there are more than one thousand aroma compounds which have been detected in wine, including alcohols, esters, fatty acids, aldehydes and terpenes, etc. (Bonino et al., 2003). In red wines, the phenolic fraction is responsible for the sensory characteristics, such as taste. Besides the grape variety, the biosynthesis of phenols and aroma compounds depends on many environmental factors, which include soil type, terrain characteristics, climate condition (especially for temperature, light and rainfall) (Jackson \& Lombard, 1993; Jiang et al., 2013; King et al., 2014; Xing et al., 2015). Some studies have demonstrated that effect of terroir factor on phenolic and volatile characteristics of wines all over the world. Li et al. (2009) stated that the geographical origins had an influence on the ployphenols content and antioxidant capacity of Cabernet Sauvignon red wines. Yue et al. (2015) reported that the number of volatile compounds in Cabernet Sauvignon red wines increased with vineyard altitude, while total concentrations of the volatiles were decreased. In Brazil, Falcão et al. (2007) reported that Cabernet Sauvignon wine from higher altitude vineyards were correlated with bell pepper flavor, while wines from lower altitudes had red fruits and jam flavor, to name a few.

Both Yantai of Shandong province (abbreviated as SDYT) and Changli of Hebei province (abbreviated as HBCL) are traditional vine-growing regions in eastern China, all wines originated from above two regions will be awarded by Chinese geographical indication wine (CGIW), which symbol means high quality wines in China. Furthermore, in recent years, China's wine industry has been developing rapidly, and new producing regions of wine have been discovered in China, including Jingyang of Shaanxi province (abbreviated as SXJY), Yuquanying of Ningxia Hui autonomous region (abbreviated as NXYQY) and Wuwei of Gansu province (abbreviated as GSWW), are situated approximately between $35^{\circ} \mathrm{N}$ to $42^{\circ} \mathrm{N}$, the latitude range is considered "golden latitude" for developing wine industry. The SXJY zone is located in the Guanzhong Plain; the NXYQY zone is on the edge of the Helan mountain; the GSWW zone is situated in Gansu Corridor, positions distributions of five wine-producing regions on the map of China were displayed in Figure 1. These soil and climate characteristics of different regions could give rise to different styles and flavors of wine. Although ecological conditions of each terroirs exists in some differences, Cabernet Sauvignon, known as a world-famous Vitis vinifera cultivars, is still the popular cultivars in most regions. 


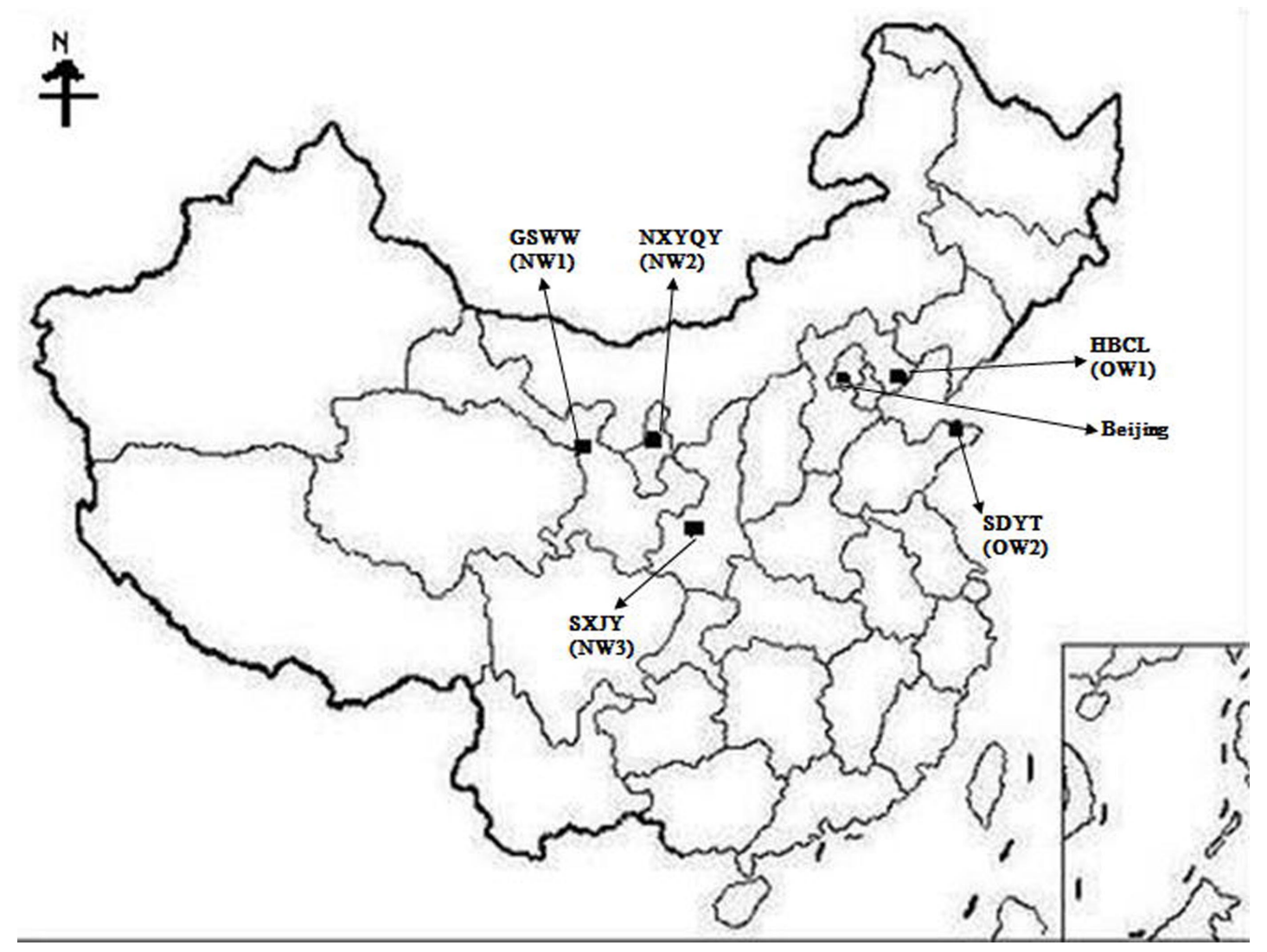

Figure 1. Position distributions of five wine-producing regions on the map of China.

However, compared with "old regions" (SDYT and HBCL regions), the phenol concentrations, total antioxidant capacity and the volatile profiles of Cabernet Sauvignon red wines from three "new regions" (SXJY, NXYQY and GSWW regions) in China remain unclear.

Hence, the aim of this work were to compare three "new regions" phenols concentrations, total antioxidant capacity and aroma profiles of Cabernet Sauvignon wines with two "old regions". The work may provide useful information for the evaluation of the characteristics of three "new regions" wines.

\section{Materials and methods}

Catechin, gallic acid, Folin-Ciocalteu's phenol reagent, neocuproine free base, 2,2-diphenyl-1-picrylhydrazyl (DPPH·), p-dimethylaminocinnamaldehyde (DMACA) and 6-hydroxy -2,5,7,8-tetramethylchroman-2-carboxylic acid (trolox) were obtained from Sigma-Aldrich (St. Louis, MO). Tris (base) was obtained from Sanland Chemical Co., Ltd (Los Angeles, CA, USA). All other solvents and chemicals used in this study were analytical reagent grade and were supplied in China.

\subsection{Sampling and winemaking procedure}

The study was carried out in 2016 vintage for five regional vineyards using Cabernet Sauvignon vines grown in commercial vineyards, grafted onto SO4 rootstock. Vines were Dulong-trained and aged 5 years. The vineyards were irrigated by drip irrigation system and the row spacing of vine was $2.5 \times 1.0 \mathrm{~m}$. Soil was managed with cover grass, grape yield per hectare was limited to 22.5 tons. The grapes were collected from five different regions, including three regions in the Northwest of China, namely the cold-cool, arid and semi-arid area (GSWW), the semi-arid and cool area (NXYQY) and the warm temperature zone (SXJY); in addition, the cool-warm and semi-humid area in North-China (HBCL) and the warm, semi-humid area in Jiaodong Peninsula (SDYT) (Table 1).

All grapes were manually harvested at commercial maturity in September to October 2016. The grapes were destemmed and crushed with an experimental destemmer-crusher, then transferred to $60 \mathrm{~L}$ stainless steel containers. Sulphur dioxide $\left(50 \mathrm{mg} \mathrm{L}^{-1}\right)$ and pectinase (30 $\mathrm{mg} \mathrm{L}^{-1}$, Lallzyme Ex) were added to the must, respectively. Saccharomyces cerevisiae strain (EC-1118, Lallemand, Danstar Ferment AG, Switzerland) active yeast $\left(200 \mathrm{mg} \mathrm{L}^{-1}\right)$ was inoculated to the musts. Alcoholic fermentation was lasted for 6 to 8 days at $20^{\circ} \mathrm{C}$ to $25{ }^{\circ} \mathrm{C}$. Temperature and density controls were monitored during fermentation. After alcoholic fermentation, the wines were separated from pomace, and then transfered to another tank for one months at $4{ }^{\circ} \mathrm{C}$. At last the wines were bottled. The wines from GSWW, NXYQY and SXJY regions were marked as NW1, NW2 and NW3, respectively; the wine samples from HBCL and SDYT regions were marked as OW1 and OW2, respectively. Residual sugar, titratable acidity, alcohol and $\mathrm{pH}$ were analyzed (Office International de la Vigne et du Vin, 1990). 
Table 1. Regional meteorological parameters and soil types from five different wine-producing regions.

\begin{tabular}{|c|c|c|c|c|c|c|c|}
\hline \multirow[b]{2}{*}{ Wine samples } & \multicolumn{7}{|c|}{ Corresponding climate and soil situation of each region } \\
\hline & $\begin{array}{c}\text { Annual mean } \\
\text { temperature }\left({ }^{\circ} \mathrm{C}\right)\end{array}$ & $\begin{array}{c}\text { Annual } \\
\text { accumulated } \\
\text { temperature }\left({ }^{\circ} \mathrm{C}\right)\end{array}$ & $\begin{array}{c}\text { Sunlight } \\
\text { duration (h) }\end{array}$ & $\begin{array}{l}\text { Precipitation } \\
\quad(\mathrm{mm})\end{array}$ & $\begin{array}{c}\text { Average altitude } \\
\text { (m above sea } \\
\text { level) }\end{array}$ & Climate types & $\begin{array}{l}\text { Regional soil } \\
\text { types }\end{array}$ \\
\hline NW2 & 8.5 & $3298-3351$ & $2800-3000$ & $150-200$ & 1036 & $\begin{array}{c}\text { Semi-arid climate } \\
\text { and cool }\end{array}$ & Gravelly soil \\
\hline OW1 & 11.0 & $3840-3990$ & $2600-2800$ & 700 & 214 & $\begin{array}{l}\text { Semi-humid, } \\
\text { cool-warm } \\
\text { climate }\end{array}$ & $\begin{array}{c}\text { Clay and sandy } \\
\text { soil }\end{array}$ \\
\hline OW2 & 12.6 & $3800-4200$ & $2550-2800$ & $750-800$ & 40 & $\begin{array}{l}\text { Warm and } \\
\text { semi-humid } \\
\text { climate }\end{array}$ & Sandy soil \\
\hline
\end{tabular}

\subsection{Determination of polyphenols}

The total phenols (TP) content was measured using the Folin-Ciocalteu (Rapisarda et al., 1999). In brief, $0.1 \mathrm{~mL}$ of wine sample and $0.5 \mathrm{~mL}$ of Folin-Ciocalteu reagent were added to a tube, and react for $5 \mathrm{~min}$ in the dark. Then $1.5 \mathrm{~mL}$ of saturated sodium carbonate solution was added to the tube, and the mixture was placed in a dark room to react for $2 \mathrm{~h}$. The absorbance of the reaction mixture was measured at $765 \mathrm{~nm}$. The result was expressed as milligrams of gallic acid equivalents per liter basis (mg GAE L $\left.{ }^{-1}\right)$.

The total flavonoids (TFO) and total flavanols (TFA) contents were determined using the colorimetric assay (Kim et al., 2003) and the DMACA method (Li et al., 1996), respectively. Both results were expressed as milligrams of catechin equivalents per liter basis (mg CTE L ${ }^{-1}$ ). The total anthocyanins (TA) content was measured using the $\mathrm{pH}$-differential method (Orak, 2007). Its content was calculated as malvidin-3-O-glucoside. The result was expressed as milligrams of malvidin-3-O-glucoside equivalents per liter basis $\left(\mathrm{ME} \mathrm{mg} \mathrm{L}^{-1}\right)$.

\subsection{Determination of antioxidant capacity}

The ability to scavenge DPPH. free radicals was measured using the method of Brandwilliams et al. (1995). In brief, $0.1 \mathrm{~mL}$ of wine sample and $3.9 \mathrm{~mL}$ of DPPH methanolic solution $\left(60 \mu \mathrm{mol} \mathrm{L}^{-1}\right)$ were mixed and kept in the dark for $30 \mathrm{~min}$. The absorbance of the reaction mixture was determined at $515 \mathrm{~nm}$. The result was expressed as micromole of trolox equivalents per liter basis $\left(\mu \mathrm{mol} \mathrm{TE} \mathrm{L}{ }^{-1}\right)$.

The cupric reducing antioxidant capacity was measured using the method of Apak et al. (2004). The result was expressed as micromole of trolox equivalents per liter basis $\left(\mu \mathrm{mol} \mathrm{TE} \mathrm{L} \mathrm{L}^{-1}\right)$.

\subsection{Extraction and analysis of sample}

Volatile compounds were extracted by HS-SPME (headspace solid phase microextraction), and gas chromatography-mass spectrometry (GC-MS) was used for the analysis as described previously (Zhang et al., 2007). $5 \mathrm{~mL}$ of wine sample and $1 \mathrm{~g}$ of sodium chloride were added to a $15 \mathrm{~mL}$ sample vial. The sample vial was heated on a heating platform agitation at $400 \mathrm{rpm}$, and was kept at $40{ }^{\circ} \mathrm{C}$ for 30 min during this period. The SPME was then inserted into the headspace, the extraction was lasted for $30 \mathrm{~min}$ with heating and agitation by a magnetic stirrer. Finally the fiber was desorbed in the GC injector at $250^{\circ} \mathrm{C}$ for $25 \mathrm{~min}$.

\subsection{GC-MS conditions}

The Gas chromatographic analysis was performed with an Agilent 7820 chromatograph coupled to an Agilent 5975 mass spectrometer. A HP-INNOWAX capillary column $(60 \mathrm{~m} \times 0.25 \mathrm{~mm}$, $0.25 \mu \mathrm{m}$ film thickness, J \& W Scientific, Folsom, CA, USA) was used. Helium was used as the carrier gas at a flow rate of $1 \mathrm{~mL} \mathrm{~min}^{-1}$. The oven temperature was programmed as follows: $12 \mathrm{~min}$ at $40{ }^{\circ} \mathrm{C}, 3{ }^{\circ} \mathrm{C} \mathrm{min}-1$ to $108{ }^{\circ} \mathrm{C}$ and holding for $2 \mathrm{~min}$, then $5{ }^{\circ} \mathrm{C} \mathrm{min}^{-1}$ to $250{ }^{\circ} \mathrm{C}$ and finally held at this temperature for $5 \mathrm{~min}$. The injector and detector were then heated to $250{ }^{\circ} \mathrm{C}$. The MS conditions were as follows: electronic impact (EI) mode at $70 \mathrm{eV}$; mass scanning range: $\mathrm{m} / z 45-550$; source temperature: $230{ }^{\circ} \mathrm{C}$. Identification of the volatile compounds was based on comparison with gas chromatographic retention times and matching against commercial libraries (NIST08. L), the GC-MS results were shown in Table 2.

\subsection{Statistical analysis}

All parameters were determined in triplicate for each sample. The analyses were carried out using SPSS 16.0 for Windows. Tuckey test $(p<0.05)$ was used to determine significant differences between means.

\section{Results and discussion}

\subsection{Phenolic groups contents}

Spectrophotometric analyses were used to determine the four phenolic subclasses contents of five different regional Cabernet Sauvignon wines from China, The experimental results are 


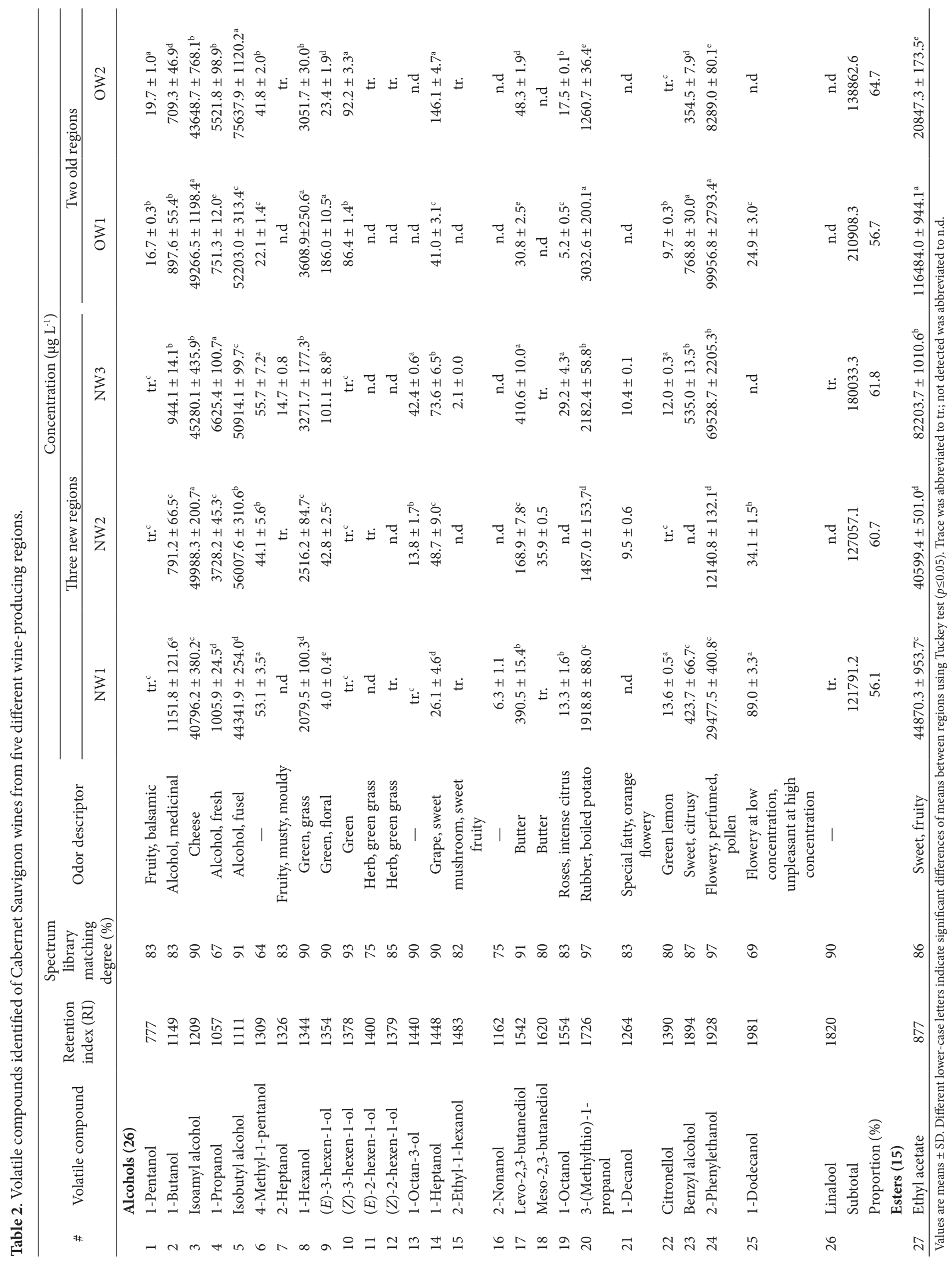




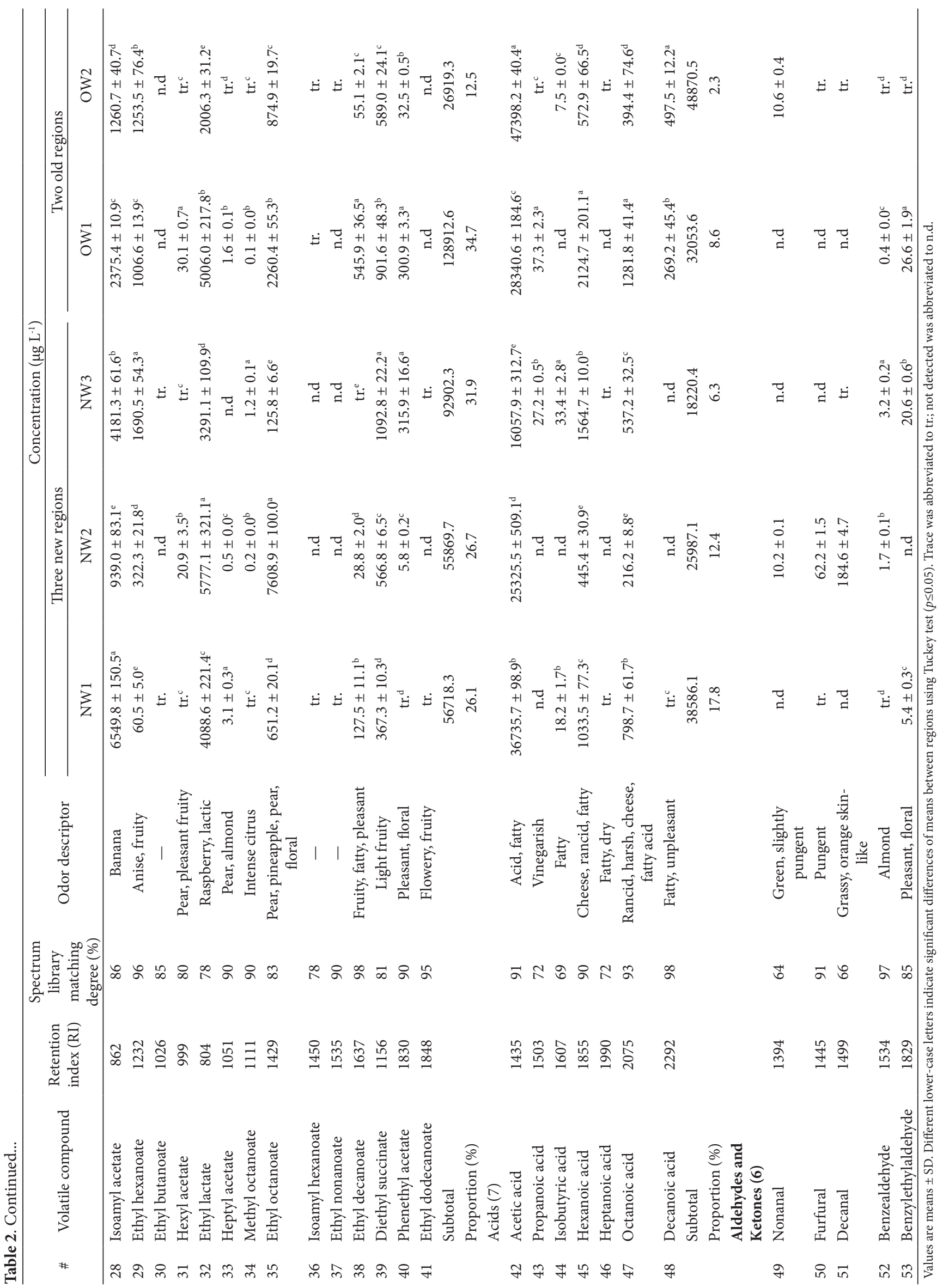




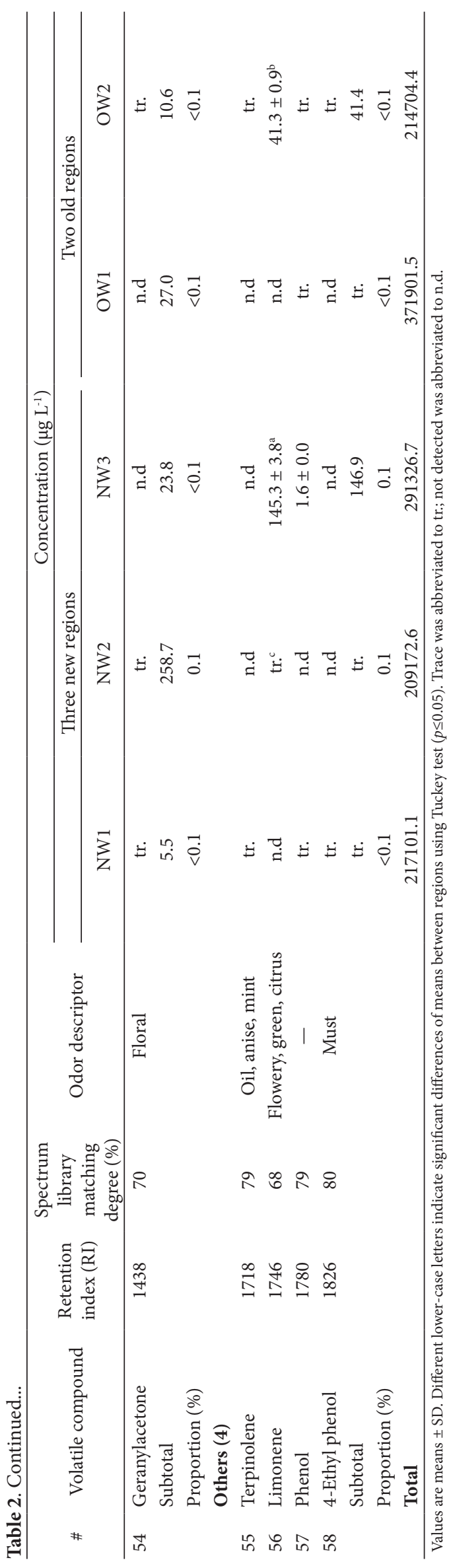


displayed in Table 3. The research showed that the amounts of the total phenols (TP) and other three main phenolic subclasses, the total flavonoids (TFO), the total flavanols (TFA) and the total anthocyanins (TA) differed to various extent amongst selected Cabernet Sauvignon wines.

The total phenols (TP) of the five regional wines ranged between 987.84 and 2244.23 (average 1505.47) $\mathrm{mg} \mathrm{GAE} \mathrm{L}^{-1}$, with significant differences among these regional wines, although these Cabernet Sauvignon wines shared similar genetic background, this result is in agreement with previous reports in the literatures (Jiang \& Zhang, 2012; Li et al., 2009). The wine from NW1 revealed the highest TP at $2244.23 \mathrm{mg} \mathrm{GAE} \mathrm{L}^{-1}$, followed by the NW3 (1564.26 $\mathrm{mg} \mathrm{GAE} \mathrm{L}^{-1}$ ), the OW1 region (1439.21 $\mathrm{mg} \mathrm{GAE} \mathrm{L}^{-1}$ ) and the NW2 (1291.80 $\mathrm{mg} \mathrm{GAE} \mathrm{L}^{-1}$ ). The OW2 showed the lowest values (987.84 $\mathrm{mg} \mathrm{GAE} \mathrm{L}^{-1}$ ) among analyzed wines. Additionally, the NW1 had about a 2 folds higher TP than OW2 region, having an approximately 1.2 to 1.5 folds higher TP than the other three regions. Compared with other regions, NW1 from GSWW region contained highly TP, and the TP of Cabernet Sauvignon wines from the rest of the world are as follows: 1260 to $1893 \mathrm{mg} \mathrm{GAE} \mathrm{L}^{-1}$ in Brazil (Granato et al., 2010), $2133 \mathrm{mg} \mathrm{GAE} \mathrm{L}^{-1}$ in Chile (Minussi et al., 2003), 1635 to $2927 \mathrm{mg} \mathrm{GAE} \mathrm{L}^{-1}$ in China (Li et al., 2009).

The five regional wines varied significantly in total flavonoids (TFO) ranging from 2529.24 to 7005.55 (average 4256.76) $\mathrm{mg} \mathrm{CTE} \mathrm{L}^{-1}$. The NW1 region exhibited the highest values of TFO, whereas the lowest TFO content was detected in the OW2 regional wines. The TFO contents from the five regional wines decreased in the following order: NW1 > NW3 > OW1 > NW2 > OW2. Furthermore, the TFO content in NW1 was nearly 3 folds those in the OW2, being approximately 1.5 to 1.8 folds than those in the other three regions.

The contents of total flavanols (TFA) varied from 223.26 to 1104.43 (average 500.07) $\mathrm{mg} \mathrm{CTE} \mathrm{L}^{-1}$. Like TP and TFA, the TFA content in NW1 showed the highest value among selected five regional Cabernet Sauvignon wines. For example, the NW1 region had about a 5 folds higher TFA content than the OW2. As one of the subclasses of phenolic compounds, it could mainly results in the astringency, bitterness and structure of wines which is particularly crucial in the stabilization of wine color during ageing (Fang et al., 2008).

Anthocyanins in wine are mainly derived from grape skin, the Cabernet Sauvignon wines total anthocyanins (TA) contents varied from 191.33 to $654.97 \mathrm{ME} \mathrm{mg} \mathrm{L}^{-1}$ among the five regions (average 359.17 $\mathrm{ME} \mathrm{mg} \mathrm{L}^{-1}$ ). The highest value of TA content was determined in NW1, which was about 3.4 folds higher than the average value, followed by NW2, OW1 and NW3, the lowest TA content was detected in OW2. The present research revealed that the contents of TA in Cabernet Sauvignon wines increased with regional altitude rising, in agreement with previous studies (Bajda, 2010; Hess, 2011), which could be due to the increase in regional altitude resulting in increased grape skin thickness. Furthermore, the interaction of low temperature, strong light and significant diurnal temperature difference at high altitude affects anthocyanins accumulation in grape skins (Yamane et al., 2006).

These values of the main phenolic groups (including TP, TFO, TFA and TA) were within the range reported for five regional Cabernet Sauvignon wines from other researchers (Li et al., 2009; Jiang \& Zhang, 2012; Ma et al., 2014). Moreover, to compare the phenolic groups of the five different regional wines, these wine samples studied almost had the same situations, including grape variety, cultivation management, ripeness, per hectare yield, vintage, wine-making technology and ageing condition, and so on. This is confirmed that the contents of the main phenolic classes vary obviously in each terroir, depending on climate and soil factors of vine growth (Li et al., 2009), as is well known. The further research on the composition and concentration of individual phenolic compounds like the flavanols, flavonols and phenilic acids families from the five regions is under progress in our laboratory. In contrast to the other regions, Cabernet Sauvignon wine from the NW1 showed the highest values of the TP, TFO, TFA and TA, respectively. Conversely, these compounds contents in OW2 were the lowest. The amounts of these compounds (including TP, TFO and TFA) in all wine samples almost decreased in the order: NW1 $>$ NW3 $>$ OW1 $>$ NW2 $>$ OW2. Based on the present study, we found that climate conditions play an key role in the regulation of biosynthesis of polyphenol in grape, resulting in significantly higher levels in polyphenol contents of grapes grown in vineyards with higher average altitude and less precipitation. This is consistent with previous study (Lee et al., 2009). Moreover, there is a positive relationship between phenolic materials and antioxidant activities (Jiang \& Zhang, 2012). In generally, as the phenolics contents in wine increased, the antioxidant activities also increased. Hence, the highest phenolic materials contents in the NW1 contribute to its increased antioxidant capacity in comparison to the other regional wines, whereas the OW2 could be little antioxidant capacity.

Table 3. Physicochemical characteristics and phenolic compound contents of Cabernet Sauvignon wines from five different wine-producing regions.

\begin{tabular}{|c|c|c|c|c|c|c|c|c|}
\hline \multirow[b]{2}{*}{ Regions } & \multirow[b]{2}{*}{$\begin{array}{l}\text { Residual sugar } \\
\qquad\left(\mathrm{g} \mathrm{L}^{-1}\right)\end{array}$} & \multirow[b]{2}{*}{$\begin{array}{c}\text { Titratable } \\
\text { acidity }\left(\mathrm{g} \mathrm{L}^{-1}\right)\end{array}$} & \multirow[b]{2}{*}{ Alcohol (\%) } & \multirow[b]{2}{*}{$\mathrm{pH}$} & \multicolumn{4}{|c|}{ Phenolic compounds } \\
\hline & & & & & $\begin{array}{c}\text { TP } \\
\left(\mathrm{mg} \mathrm{GAE} \mathrm{L}^{-1}\right)\end{array}$ & $\begin{array}{c}\text { TFO } \\
\left(\mathrm{mg} \mathrm{CTE} \mathrm{L}^{-1}\right)\end{array}$ & $\begin{array}{c}\text { TFA } \\
\left(\mathrm{mg} \mathrm{CTE} \mathrm{L}^{-1}\right)\end{array}$ & $\begin{array}{c}\mathrm{TA} \\
\left(\mathrm{ME} \mathrm{mg} \mathrm{L}^{-1}\right)\end{array}$ \\
\hline NW1 & $1.8 \pm 0.0^{\mathrm{a}}$ & $6.5 \pm 0.2^{b}$ & $11.9 \pm 0.4^{\mathrm{a}}$ & $3.3 \pm 0.1^{\mathrm{a}}$ & $2244.23 \pm 73.1^{\mathrm{a}}$ & $7005.55 \pm 131.1^{\mathrm{a}}$ & $1104.43 \pm 67.6^{a}$ & $654.97 \pm 14.9^{a}$ \\
\hline NW2 & $2.1 \pm 0.1^{\mathrm{a}}$ & $6.7 \pm 0.1^{b}$ & $12.0 \pm 0.3^{\mathrm{a}}$ & $3.1 \pm 0.0^{\mathrm{ab}}$ & $1291.80 \pm 35.9^{c}$ & $3599.03 \pm 59.5^{c}$ & $275.02 \pm 5.6^{c}$ & $434.13 \pm 5.4^{\mathrm{b}}$ \\
\hline NW3 & $1.9 \pm 0.2^{\mathrm{a}}$ & $7.3 \pm 0.2^{\mathrm{a}}$ & $11.9 \pm 0.6^{\mathrm{a}}$ & $3.2 \pm 0.2^{\mathrm{a}}$ & $1564.26 \pm 73.8^{\mathrm{b}}$ & $4113.27 \pm 23.5^{\mathrm{b}}$ & $425.79 \pm 5.3^{b}$ & $237.70 \pm 3.5^{c}$ \\
\hline OW1 & $2.0 \pm 0.0^{\mathrm{a}}$ & $7.0 \pm 0.0^{\mathrm{a}}$ & $12.2 \pm 0.5^{\mathrm{a}}$ & $3.0 \pm 0.1^{\mathrm{b}}$ & $1439.21 \pm 41.4^{\mathrm{b}}$ & $4036.70 \pm 81.2^{\mathrm{b}}$ & $471.84 \pm 1.0^{\mathrm{b}}$ & $277.70 \pm 2.8^{c}$ \\
\hline OW2 & $1.3 \pm 0.1^{\mathrm{b}}$ & $6.7 \pm 0.3^{\mathrm{b}}$ & $11.8 \pm 0.1^{\mathrm{a}}$ & $3.1 \pm 0.2^{\mathrm{ab}}$ & $987.84 \pm 12.2^{\mathrm{d}}$ & $2529.24 \pm 209.8^{\mathrm{d}}$ & $223.26 \pm 1.6^{c}$ & $191.33 \pm 3.7^{\mathrm{d}}$ \\
\hline
\end{tabular}

Values are means \pm SD. Different lower-case letters indicate significant differences of means between regions using Tuckey test ( $p \leq 0.05)$. Titratable acidity concentration was expressed as tartaric acid equivalent. 


\subsection{Antioxidant capacity}

To evaluate the antioxidant levels of each wine samples, the antioxidant capacities found by two different methods in Cabernet Sauvignon red wines from the five regions differed greatly (Figure 2).

$\mathrm{DPPH} \cdot$ method is one of the most popular method for detecting antioxidant activity of wine (Wang, 2008). In here, the five regional wines was measured using the DPPH. methods, the results studied were displayed in Figure 2A. For DPPH., the average antioxidant activity was $8138.57 \mu \mathrm{mol} \mathrm{TE} \mathrm{L}^{-1}$, ranging from 5078.31 to $12333.04 \mu \mathrm{mol} \mathrm{TE} \mathrm{L}^{-1}$. The values of DPPH. reduced in this order: NW1 $>$ OW $1>$ NW3 $>$ NW2 $>$ OW 2 . The experimental results indicate that the higher the amount of antioxidant, the lower is the concentration of remaining DPPH. and the stronger is the radical-scavenging activity. The five regional analyzed wines displayed obvious antioxidant capacity with the CUPRAC method (Figure 2B). For CUPRAC, the average antioxidant activity was $13856.89 \mu \mathrm{mol} \mathrm{TE} \mathrm{L}^{-1}$, ranging from

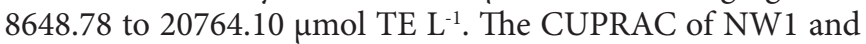
NW3 with the maximum values was almost 2.4 folds and 1.6 fold higher than those of the OW2, respectively. The values of CUPRAC decreased according to the order: NW1 > OW1 > NW3 > NW2 > OW2.

The NW1 had the highest antioxidant values (12333.04 $\mu \mathrm{M} \mathrm{TE} \mathrm{L}^{-1}$ for DPPH. and $20764.10 \mu \mathrm{M} \mathrm{TE} \mathrm{L}^{-1}$ for CUPRAC), followed by NW3, NW2 and OW1, while the lowest appears in the OW2 regional (5078.31 $\mu \mathrm{M} \mathrm{TE} \mathrm{L}^{-1}$ for DPPH. and $8648.78 \mu \mathrm{M} \mathrm{TE} \mathrm{L}^{-1}$ for CUPRAC). The different degree rests with the method selected. Other authors have also drawn the same conclusion (Li et al., 2009; Meng et al., 2012). Compared with Cabernet Sauvignon red wines from Henan and Beijing regions of China (Li et al., 2009), the antioxidant capacity of NW1 from GSWW region was higher. In addition, for all the Cabernet Sauvignon wines, this result is well matched the antioxidant capacity with the phenolics contents. This may be due to the possibility that phenolic compounds including TP, TFO and TFA are known to determine antioxidant capacity in wine analyzing.

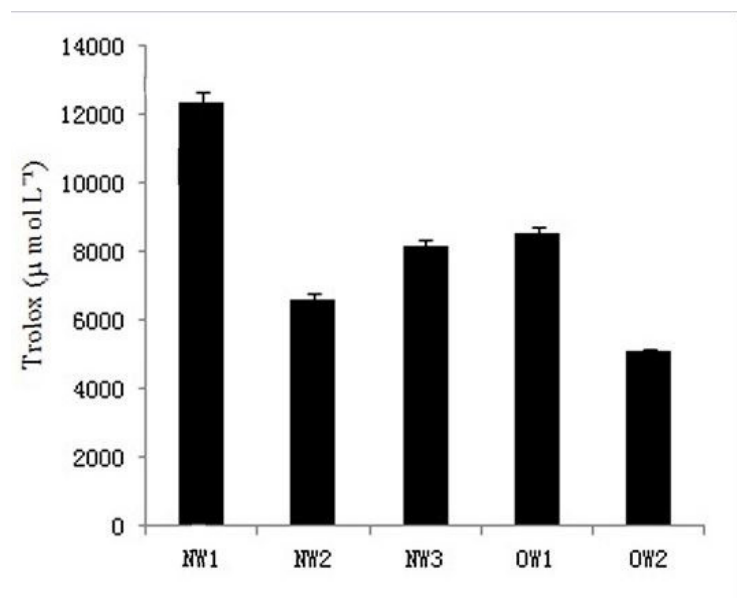

A

\subsection{Volatile composition}

All 58 and 51 compounds were separately identified and quantified in three "new regions" and two "old regions" Cabernet Sauvignon wines by GC-MS with HS-SPME, mainly higher alcohols (26), esters (15), acids (7), aldehydes and ketones (6), and terpene and phenol compounds (4) (Table 2). The majority of these aroma compounds are usually detected in all of the wines, and being at varying levels, which are derived from grapes and yeast strain during the fermentation process. Furthermore, both alcohols and esters were the largest two groups of volatile compounds in terms of the number and concentration of volatile compounds detected in all wine samples, accounting for about $56.1 \%$ to $64.7 \%$ and $12.5 \%$ to $34.7 \%$, respectively, followed by acids, in agreement with previous reports (Cheng et al., 2015; Yue et al., 2015).

\section{Alcohols}

Alcohols are formed from the degradation of carbohydrates, amino acids and lipids (Antonelli et al., 1999). The composition and concentration of alcohols differed to various extent among the three "new regions" and two "old regions" Cabernet Sauvignon wines, there were 26 and 21 types of alcohols identified, respectively. The subtotal content of alcohols in the three "new regions" and the two "old regions" wines was from 121.8 to $180.0 \mathrm{mg} \mathrm{L}^{-1}$ and from 138.9 to $210.9 \mathrm{mg} \mathrm{L}^{-1}$, respectively, which was separately $56.1-61.8 \%$ and $56.7-64.7 \%$ of the total volatile compounds detected. Isobutyl alcohol, isoamyl alcohol and 2-phenylethanol were the most amount of alcohols, accounting for $92-96 \%$ of the total alcohols contents in all wine samples, these results are in agreement with previous literatures (Cheng et al., 2015; Yue et al., 2015). Both of isobutyl alcohol and isoamyl alcohol had highest concentration in OW2 and NW2, respectively, furthermore, isoamyl alcohol had a cheese aroma, which could be the potential impact odorant in present study, inducing a positive role to overall aroma of wine (Lorenzo et al., 2008). Moreover, the 2-phenylethanol has the highest concentration in OW1 and NW3, which is correlated with flowery and perfumed

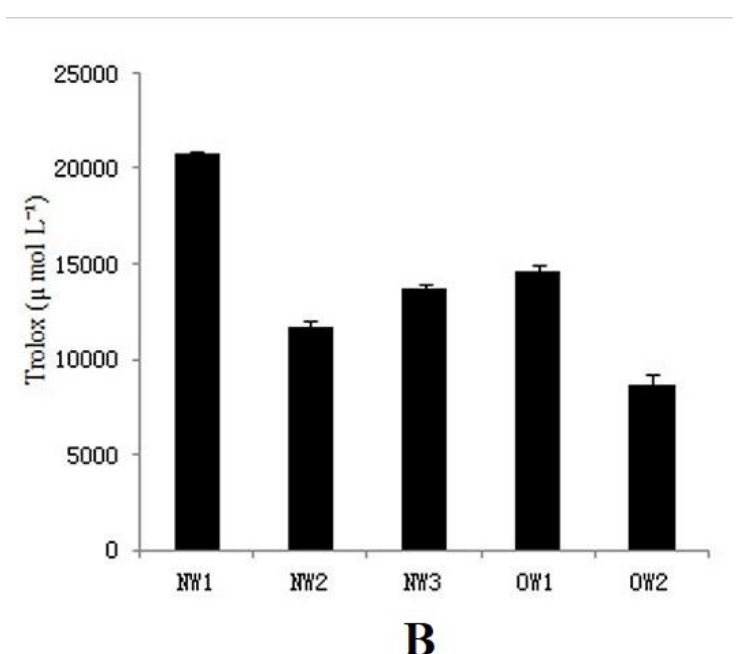

Figure 2. Antioxidant capacity of Cabernet Sauvignon wine samples from five wine-producing regions, detected using two kinds of methods: (A) DPPH. scavenging activity; and (B) CUPRAC method. 
aromas (Sánchez Palomo et al., 2007). With the exception of aforesaid three compounds, 1-propanol, 1-hexanol, 1-butanol, benzyl alcohol and 3-(methylthio)-1-propanol were also higher concentration in all regional wines, they were the main alcohol profiles of all wine sampled. The five missing alcohols in the two "old regions" wines were 1-octan-3-ol, 2-nonanol, meso-2,3-butanediol, 1-decanol and linalool, but all of them were only present in lower amounts.

\section{Esters}

Esters were the second most abundant class in terms of the number and concentration of volatiles in the five regional wines. The subtotal concentration of esters in the three "new regions" and the two "old regions" wines was from 55.9 to $92.9 \mathrm{mg} \mathrm{L}^{-1}$ and from 26.9 to $128.9 \mathrm{mg} \mathrm{L}^{-1}$, respectively, which was separately $26.1-31.9 \%$ and $12.5-34.7 \%$ of the total volatile compounds measured. The composition and concentrations of esters were significant differences in the five regional wines, especially for some compounds of lower amounts.

Ethyl esters of fatty acids are synthesized during fermentation, their concentration of which is dependent on sugar content, fermentation temperature, yeast strain and aeration degree (Perestrelo et al., 2006). In this study, 8 ethyl esters were identified in five regional wines, the esters of this class play a positive role in the general quality of wine, because most of them release the typical fruity flavor (Francioli et al., 2003). As shown in Table 2, ethyl acetate, ethyl lactate, ethyl octanoate and ethyl hexanoate exhibited the largest concentration among the ethyl esters, this was coincident with other studies on Cabernet Sauvignon wines (Jiang et al., 2013), especially for ethyl acetate, its concentration accounted for $72.7-90.4 \%$ of the total ester in five regional wines, its concentration decreased as the following order: OW1 $>$ NW3 $>$ NW1 > NW2 > OW2, the higher concentration of ethyl acetate would give stronger fruity and sweet flavors in corresponding wine. The composition and concentration of the volatile compounds in wine-grape are regulated by some ecological factors, especially for the compounds with low content.

Acetate esters are the production of the reaction between acetyl-CoA and higher alcohols (Perestrelo et al., 2006). The following acetate esters were identified, including isoamyl acetate, heptyl acetate, hexyl acetate and phenethyl acetate, they could contribute to quality in young wines (Lambrechts \& Pretorius, 2000; Ferreira et al., 2000). In our study, with the exception of isoamyl acetate, other 3 compounds of acetate esters were all with low concentration. However, the concentrations of isoamyl acetate exhibited significant differences in the five regional wines. The concentration of the isoamyl acetate decreased as the following order: NW1 $>$ NW3 $>$ OW $1>$ OW2 $>$ NW2. The concentration of the isoamyl acetate in the NW1 were separately 2.8 and 5.1 folds that in OW1 and OW2, its content in the NW3 were nearly 1.7 and 3.3 times that in the OW1 and OW2, respectively. Because the isoamyl acetate usually resulted in banana notes (Sánchez Palomo et al., 2007), compared with the OW1 and OW2, the NW1 and NW3 would exhibit prominent fruity aromas due to the highest concentration of isoamyl acetate.
Acids

The synthesis of fatty acids mainly rests with the components of the must and fermentation conditions (Schreier \& Jennings, 1979). Seven different acids were identified in five regional wines, the subtotal content of acids in the three "new regions" and the two "old regions" wines was from 18.2 to $38.6 \mathrm{mg} \mathrm{L}^{-1}$ and from 32.1 to $48.9 \mathrm{mg} \mathrm{L}^{-1}$, respectively, which was separately $6.3-17.8 \%$ and $2.3-8.6 \%$ of the total volatile compounds measured. Acetic acid was the largest concentration among the acids found, followed by hexanoic acid and octanoic acid. Acetic acid is usually formed during fermentation. Acetic acid could lead to the wine tasting sour and thin which was at high level; however, acetic acid strengthens wine flavors which was at low level (Joyeux et al., 1984). Like other acids, hexanoic acid, isobutyric acid, octanoic acid and decanoic acid could not directly affect wine quality, but are closely associated with the complexity of the aroma. In the current study, the concentration of acid were significant differences in five regional wines, the average value of total acid content in two "old regions" wines was nearly 1.5 fold higher than the average value in three "new region" wines. The appropriate content of acids is the guarantee of the production of volatile esters in wine. These C6 to C10 fatty acids can strengthen the complexity of wine flavors which was at concentrations of 4 to $10 \mathrm{mg} \mathrm{L}^{-1}$, and endow wine with mild and pleasant flavors; whereas, when their concentration was beyond $20 \mathrm{mg} \mathrm{L}^{-1}$, they will have a negative impact on wine (Shinohara, 1985). In the present study, the C6 to C10 fatty acids at concentration all far below $10 \mathrm{mg} \mathrm{L}^{-1}$, so they might contribute to a positive impact on the flavors of five regional Cabernet Sauvignon wines examined.

\section{Ketones and aldehydes}

Ketones and aldehydes are formed from the oxidative degradation of sugars and amino acids, or from the oxidation of corresponding alcohols. Six types of ketones and aldehydes were identified in five Cabernet Sauvignon wine samples, total concentration of which were from 5.5 to $258.7 \mu \mathrm{g} \mathrm{L}^{-1}$. Of these compounds, only benzealdehyde was found in all the wine studied. Except for NW2, the total concentration of the ketones and aldehydes in other four regional wines was not much difference.

\section{Other compounds}

Terpenes belong to the plant secondary metabolites, in which biosynthesis begins with acetyl-CoA or there is another biosynthetic via, involving glyceraldehyde 3-phosphate and pyruvate. Precursors depends on the sub-group of terpenoids. In the present study, both of terpinolene and limonene were found in five regional wines. The terpinolene was only detected in the NW1 and OW2, limonene in NW2, NW3 and OW2, moreover, the concentrations of limonene in NW3 and OW2 from two warm regions with higher annual mean temperatures were the highest among five regional wines, the finding is consistent with the result of previous study which vineyard location has a significant impact on flavors and wine quality by demonstrating that warm sites in Italy can contribute to high monoterpene concentrations (Corino \& Stefano, 1988). The phenol, volatile phenols and 4-ethyl phenol can also influence the overall flavor of the wine. Both of he metabolic activity of yeasts and oak 


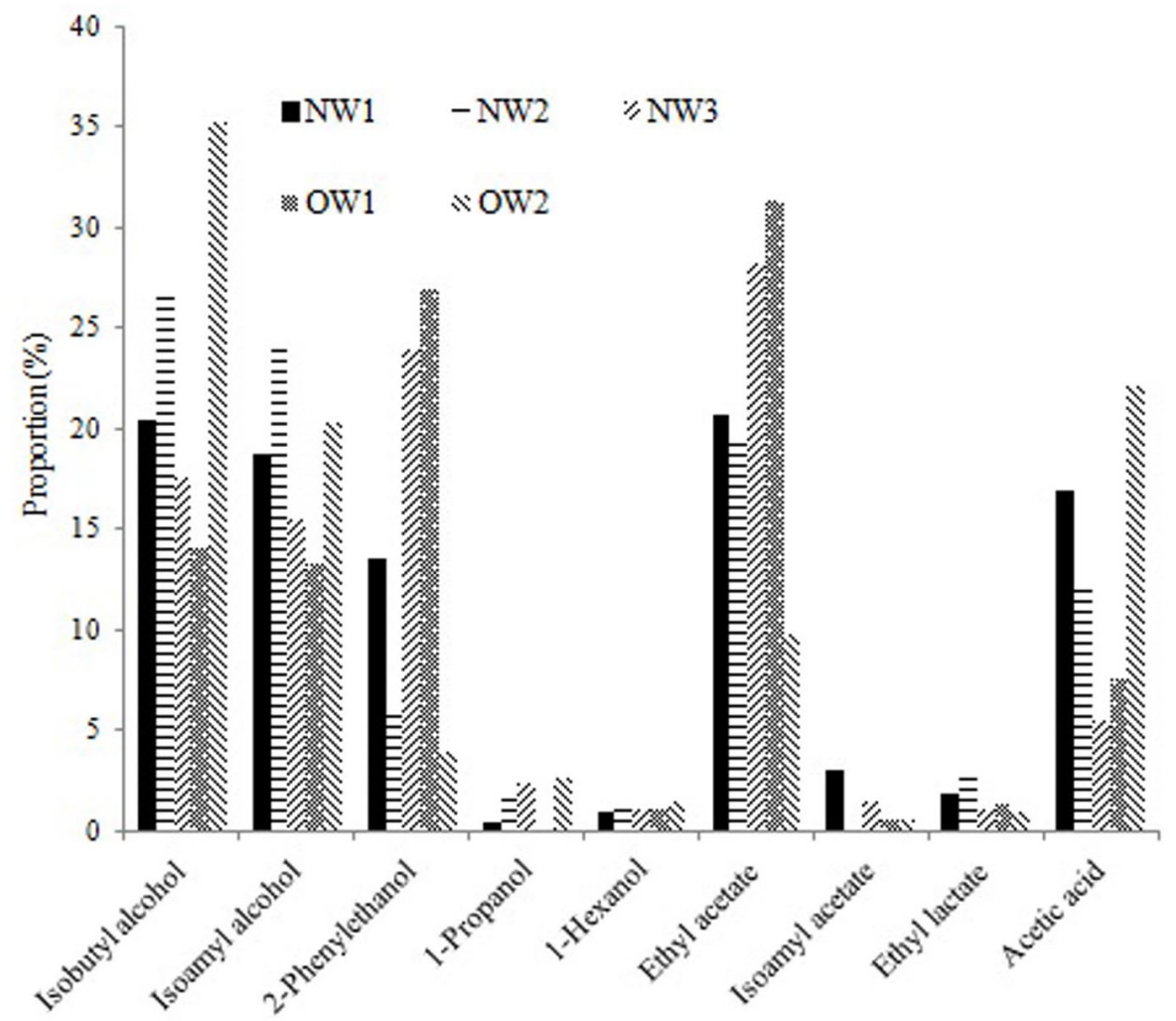

Figure 3. The proportion (\%) of nine main aroma components in each regional Cabernet Sauvignon wines.

maturation can usually increase the amounts of volatile phenols in wine. In the current study, either 4-ethyl phenol and phenol with very low concentration was identified in all of wines, or only existed in trace amounts.

Taking into account the concentration of each volatile compound detected, the volatile profiles for the Cabernet Sauvignon red wines from the five different regions were displayed in Figure 3. As shown Figure 3, nine volatile compounds were considered to be the most powerful odorants in all wines with the concentration being apparently higher than other compounds detected, including isobutyl alcohol, isoamyl alcohol, 1-propanol, 2-phenylethanol, ethyl acetate, 1-hexanol, isoamyl acetate, ethyl lactate and acetic aicd. According to their odor descriptor, cheese, floral and fruity seem to be relevant to the five regional Cabernet Sauvignon wines. Moreover, for upper nine compounds, their concentration existed discrepancy in different extent. These results can draw a conclusion that the differences of volatile compounds should be contributed to terroir factor. Furthermore, this study and previous research suggests that the position of vineyard plays an important role in regulating the composition and concentration of the wine flavor (Jiang et al., 2013).

\section{Conclusion}

In this work we demonstrate the effects of terroir on the phenol, total antioxidant capacity and volatile components of Cabernet Sauvignon wines from three "new regions" (NW1, NW2 and NW3) and two "old regions" (OW1 and OW2). Knowing the environmental conditions could lead to these differences in the phenol, antioxidant activities and volatile components of all wine samples. The contents of phenolic classes (including total phenols, total flavonoids and total flavanols) and antioxidant activities from NW1 were significantly the highest among five regional wines, the latter were NW3, OW1 and $\mathrm{NW} 2$, these parameters in OW2 were the lowest. after NW1, but the contents of total anthocyanins in the NW2 was the second-highest than both OW1 and NW3. All 58 and 51 volatile compounds were separately identified in three "new regions" and two "old regions" Cabernet Sauvignon wines, the aroma fraction was constituted mainly alcohols, followed by esters and fatty acid. Nine volatile compounds were considered to be the most powerful odorants in all of wines with the largest amounts, including isobutyl alcohol, isoamyl alcohol, 2-phenylethanol, 1-propanol, ethyl acetate, 1-hexanol, isoamyl acetate, ethyl lactate and acetic aicd. According to their odor descriptor, cheese, floral and fruity could be relevant to the overall flavors of the three new regional Cabernet Sauvignon wines. To summarize, the phenol, total antioxidant capacity and aroma components of Cabernet Sauvignon wines can be affected by "terroir" factor; three new regions, GSWW, NXYQY and SXJY regions have a big potential for producing high quality Cabernet Sauvignon wines.

\section{Acknowledgements}

The authors are thankful to Mr Junxian Zhang and Mrs Rui Wang for them providing part grape samples. This work was supported by Sci-Tech Research and Development Project of Shaanxi Province (Project 2015KJXX-98) and Sci-Tech Research and Development Project of Weinan City (Project 2015KYJ-4-3). 


\section{References}

Antonelli, A., Castellari, L., Zambonelli, C., \& Carnacini, A. (1999). Yeast influence on volatile composition of wines. Journal of Agricultural and Food Chemistry, 47(3), 1139-1144. http://dx.doi.org/10.1021/ jf9807317. PMid:10552428.

Apak, R., Guclu, K., Ozyurek, M., \& Karademir, S. E. (2004). Novel total antioxidant capacity index for dietary polyphenols and vitamins $\mathrm{C}$ and $\mathrm{E}$, using their cupricion reducing capability in the presence of neocuproine: CUPRAC method. Journal of Agricultural and Food Chemistry, 52(26), 7970-7981. http://dx.doi.org/10.1021/jf048741x. PMid:15612784.

Bajda, A. (2010). Review of high elevation viticulture and winemaking research. Oregon: South Oregon University Geography Department. Retrieved from http://www.theelevationofwine.org/research

Bonino, M., Schellino, R., Rizzi, C., Aigotti, R., Delfini, C., \& Baiocchi, C. (2003). Aroma compounds of an Italian wine (Ruche) by HS-SPME analysis coupled with GC-ITMS. Food Chemistry, 80(1), 125-133. http://dx.doi.org/10.1016/S0308-8146(02)00340-0.

Brandwilliams, W., Cuvelier, M. E., \& Berset, C. (1995). Use of a free-radical method to evaluate antioxidant activity. LebensmittelWissenschaft + Technologie, 28(1), 25-30. http://dx.doi.org/10.1016/ S0023-6438(95)80008-5.

Cheng, G., Liu, Y., Yue, T. X., \& Zhang, Z. W. (2015). Comparison between aroma compounds in wines from four Vitis vinifera grape varieties grown in different shoot positions. Food Science and Technology, 35(2), 237-246. http://dx.doi.org/10.1590/1678-457X.6438.

Corino, L., \& Stefano, D. R. (1988). Response of white Muscat grapes in relation to various growing environments and evaluation of systems for training and pruning. Rivista di Viticoltura e di Enologia, 41, 72-85.

Falcão, L. D., De Revel, G., Perello, M. C., Moutsiou, A., Zanus, M. C., \& Bordignon-Luiz, M. T. (2007). A survey of seasonal temperatures and vineyard altitude influences on 2-methoxy-3-isobutylpyrazine, C13-norisoprenoids, and the sensory profile of Brazilian Cabernet sauvignon wines. Journal of Agricultural and Food Chemistry, 55(9), 3605-3612. http://dx.doi.org/10.1021/jf070185u. PMid:17394344.

Fang, F., Li, J. M., Zhang, P., Tang, K., Wang, W., Pan, Q. H., \& Huang, W. D. (2008). Effects of grape variety, harvest date, fermentation vessel and wine ageing on flavonoid concentration in red wines. Food Research International, 41(1), 53-60. http://dx.doi.org/10.1016/j. foodres.2007.09.004.

Ferreira, V., Lápez, R., \& Cacho, J. F. (2000). Quantitative determination of the odorants of young red wines from different grape varieties. Journal of the Science of Food and Agriculture, 80(11), 1659-1667. http://dx.doi.org/10.1002/1097-0010(20000901)80:11<1659::AIDJSFA693>3.0.CO;2-6.

Francioli, S., Torrens, J., Riu-Aumatell, M., López-Tamames, E., \& Buxaderas, S. (2003). Volatile compounds by SPME-GC as age markers of sparkling wines. American Journal of Enology and Viticulture, 54(3), 158-162.

Granato, D., Katayama, F. C. U., \& Castro, I. A. (2010). Assessing the association between phenolic compounds and the antioxidant activity of Brazilian red wines using chemometrics. LebensmittelWissenschaft + Technologie, 43(10), 1542-1549. http://dx.doi. org/10.1016/j.lwt.2010.05.031.

Hess, S. (2011). Exploring high altitude viticulture. Mendoza: Bodega Catena Zapata. Retrieved from http://www.theelevationofwine. org/press

Jackson, D. I., \& Lombard, P. B. (1993). Environmental and management practices affecting grape composition and wine quality-a review. American Journal of Enology and Viticulture, 44(4), 409-430.
Jiang, B., \& Zhang, Z. W. (2012). Comparison on penolic compounds and antioxidant properties of Cabernet Sauvignon and Merlot wines from four wine grape-growing regions in China. Molecules, 17(8), 8804-8821. http://dx.doi.org/10.3390/molecules17088804. PMid:22832882.

Jiang, B., Xi, Z. M., Luo, M. J., \& Zhang, Z. W. (2013). Comparison on aroma compounds in Cabernet Sauvignon and Merlot wines from four wine grape-growing regions in China. Food Research International, 51(2), 482-489. http://dx.doi.org/10.1016/j.foodres.2013.01.001.

Joyeux, A., Lafon-Lafourcade, S., \& Ribéreau-Gayon, P. (1984). Evolution of acetic acid bacteria during fermentation and storage of wine. Applied and Environmental Microbiology, 48(1), 153-156. PMid:16346581.

Katalinić, V., Možina, S. S., Skroza, D., Generalić, I., Abramovič, H., Miloš, M., Ljubenkov, I., Piskernik, S., Pezo, I., \& Terpinc, P. (2010). Polyphenolic profile, antioxidant properties and antimicrobial activity of grape skin extracts of 14 Vitis vinifera varieties grown in Dalmatia (Croatia). Food Chemistry, 119(2), 715-723. http://dx.doi. org/10.1016/j.foodchem.2009.07.019.

Kim, S., Jin, Y., Choi, Y., \& Park, T. (2011). Resveratrol exerts anti-obesity effects via mechanisms involving down-regulation of adipogenic and inflammatory process in Mice. Biochemical Pharmacology, 81(11), 1343-1351. http://dx.doi.org/10.1016/j.bcp.2011.03.012. PMid:21439945.

Kim, D. O., Chun, O. K., Kim, Y. J., Moon, H. Y., \& Lee, C. Y. (2003). Quantification of polyphenolics and their antioxidant capacity in fresh plums. Journal of Agricultural and Food Chemistry, 51(22), 6509-6515. http://dx.doi.org/10.1021/jf0343074. PMid:14558771.

King, E. S., Stoumen, M., Buscema, F., Hjelmeland, A. K., Ebeler, S. E., Heymann, H., \& Boulton, R. B. (2014). Regional sensory and chemical characteristics of Malbec wines from Mendoza and California. Food Chemistry, 143(7), 256-267. http://dx.doi.org/10.1016/j. foodchem.2013.07.085. PMid:24054238.

Lambrechts, M. G., \& Pretorius, I. S. (2000). Yeast its importance to wine aroma: a review. South African Journal of Enology and Viticulture, 21, 97-129.

Lee, J. E., Hwang, G. S., Van Den Berg, F., Lee, C. H., \& Hong, Y. S. (2009). Evidence of vintage effects on grape wines using $1 \mathrm{H}$ NMRbased metabolomic study. Analytica Chimica Acta, 648(1), 71-76. http://dx.doi.org/10.1016/j.aca.2009.06.039. PMid:19616691.

Li, H., Wang, X. Y., Li, Y., Li, P. H., \& Wang, H. (2009). Polyphenolic compounds and antioxidant properties of selected China wines. Food Chemistry, 112(2), 454-460. http://dx.doi.org/10.1016/j. foodchem.2008.05.111.

Li, Y. G., Tanner, G., \& Larkin, P. (1996). The DMACA-HCl protocol and the threshold proanthocyanidin content for bloat safety in forage legumes. Journal of the Science of Food and Agriculture, 70(1), 89-101. http://dx.doi.org/10.1002/(SICI)1097-0010(199601)70:1<89::AIDJSFA470>3.0.CO;2-N.

Lorenzo, C., Pardo, F., Zalacain, A., Alonso, G. L., \& Rosario Salinas, M. (2008). Complementary effect of Cabernet Sauvignon on Monastrell wines. Journal of Food Composition and Analysis, 21(1), 54-61. http:// dx.doi.org/10.1016/j.jfca.2007.06.003.

Ma, T. T., Sun, X. Y., Gao, G. T., Wang, X. Y., Liu, X. Y., Du, G. R., \& Zhan, J. C. (2014). Phenolic characterisation and antioxidant capacity of young wines made from different grapevarieties gwn in Helanshan Donglu wine zone (China). South African Journal of Enology and Viticulture, 35(2), 321-331. http://dx.doi.org/10.21548/35-2-1020.

Meng, J. F., Fang, Y. L., Qin, M. Y., Zhuang, X. F., \& Zhang, Z. W. (2012). Varietal differences among the phenolic profiles and antioxidant properties of four cultivars of spine grape (Vitis davidii Foex) in 
Chongyi County (China). Food Chemistry, 134(4), 2049-2056. http://dx.doi.org/10.1016/j.foodchem.2012.04.005. PMid:23442655.

Minussi, R. C., Rossi, M., Bologna, L., Cordi, L., Rotilio, D., Pastore, G. M., \& Duran, N. (2003). Phenolic compounds and total antioxidant potential of commercial wines. Food Chemistry, 82(3), 409-416. http://dx.doi.org/10.1016/S0308-8146(02)00590-3.

Office International de la Vigne et du Vin - OIV. (1990). Recueil des methods internationales d'analyse des vins et des moûts. Paris: OIV.

Orak, H. H. (2007). Total antioxidant activities, phenolics, anthocyanins, polyphenol oxidase activities of selected red grape cultivars and their correlations. Scientia Horticulturae, 111(3), 235-241. http:// dx.doi.org/10.1016/j.scienta.2006.10.019.

Perestrelo, R., Fernandes, A., Albuquerque, F. F., Marques, J. C., \& Camara, J. S. (2006). Analytical characterization of the aroma of Tinta Negra Mole red wine: Identification of the main odorants compounds. Analytica Chimica Acta, 563(1), 154-164. http://dx.doi. org/10.1016/j.aca.2005.10.023.

Rapp, A. (1998). Volatile flavour of wine: correlation between instrumental analysis and sensory perception. Nahrung-Food, 42(6), 351-363. http://dx.doi.org/10.1002/(SICI)1521-3803(199812)42:06<351::AIDFOOD351>3.3.CO;2-U. PMid:9881361.

Rapisarda, P., Tomaino, A., Lo Cascio, R., Bonina, F., De Pasquale, A., \& Saija, A. (1999). Antioxidant effectiveness as influenced by phenolic content of fresh orange juices. Journal of Agricultural and Food Chemistry, 47(11), 4718-4723. http://dx.doi.org/10.1021/ jf990111l. PMid:10552879.

Rodriguez-Nogales, J., Fernandez-Fernandez, E., \& Vila-Crespo, J. (2009). Characterization and classification Spanish verdejo young white wines by volatile and sensory analysis with chemometric tools. Journal of the Science of Food and Agriculture, 89(11), 1927-1935. http://dx.doi.org/10.1002/jsfa.3674.

Sánchez Palomo, E., Díaz-Maroto, M. C., Viñas, M. A. G., SorianoPérez, A., \& Pérez-Coello, M. S. (2007). Aroma profile of wines from Albillo and Muscat grape varieties at different stages of ripening. Food Control, 18(5), 398-403. http://dx.doi.org/10.1016/j. foodcont.2005.11.006.

Schreier, P., \& Jennings, W. G. (1979). Flavor composition of wines: a review. Critical Reviews in Food Science and Nutrition, 12(1), 59111. http://dx.doi.org/10.1080/10408397909527273. PMid:389563.

Shinohara, T. (1985). Gas chromatographic analysis of volatile fatty acids in wines. Agricultural and Biological Chemistry, 49(7), 22112212. http://dx.doi.org/10.1271/bbb1961.49.2211.

Stockham, K., Sheard, A., Paimin, R., Buddhadasa, S., Duong, S., Orbell, J. D., \& Murdoch, T. (2013). Comparative studies on the antioxidant properties and polyphenolic content of wine from different growing regions and vintages, a pilot study to investigate chemical markers for climate change. Food Chemistry, 140(3), 500-506. http://dx.doi. org/10.1016/j.foodchem.2013.01.006. PMid:23601398.

Wang, X. Y. (2008). Study on antioxidant activity of wine and its detection method (DPhil dissertation). Northwest A\& F University, Yangling, Shaanxi, China.

Xing, R. R., He, F., Xiao, H. L., Duan, C. Q., \& Pan, Q. H. (2015). Accumulation pattern of favonoids in Cabernet Sauvignon grapes grown in a low-latitude and high-altitude region. South African Journal of Enology and Viticulture, 36(1), 32-43.

Yamane, T., Jeong, S., Goto-Yamamoto, N., Koshita, Y., \& Kobayashi, S. (2006). Effects of temperature on anthocyanin biosynthesis in grape berry skins. American Journal of Enology and Viticulture, 57(1), 54-59.

Yue, T. X., Chi, M., Song, C. Z., Liu, M. Y., Meng, J. F., Zhang, Z. W., \& Li, M. H. (2015). Aroma characterization of Cabernet Sauvignon wine from the Plateau of Yunnan (China) with different altitudes using SPME-GC/MS. International Journal of Food Properties, 18(7), 1584-1596. http://dx.doi.org/10.1080/10942912.2014.923442.

Zhang, M. X., Xu, Q., Duan, C. Q., Qu, W. Q., \& Wu, Y. W. (2007). Comparative study of aromatic compounds in young red wines from Cabernet Sauvignon, Cabernet Flanc and Cabernet Gernischet varieties in China. Journal of Food Science, 72(5), 248-252. http:// dx.doi.org/10.1111/j.1750-3841.2007.00357.x. PMid:17995710. 